\title{
Congenital intestinal stenosis and Hirschsprung's disease: two extremely rare pathologies in a newborn puppy
}

Angélica Morales-Miranda

\begin{abstract}
Background: Hirschsprung's disease (HSCR) is a common congenital malformation of the enteric nervous system (ENS). During fetal development, ganglion cells of the ENS are derived from neural crest cells that migrate to the bowel. These cells reside principally in two ganglionated plexus: 1) The myenteric plexus, extending from the esophagus to the anus, and 2) submucous plexus, extending from the duodenum to the anus. In large animal species, there is a third plexus called Henle's or Schabadasch's plexus.

ENS ganglion cells play a key role in normal gastrointestinal motility, respond to sensory stimuli and regulate blood flow. Both plexus show a high degree of independence from the central nervous system. Alterations in the embryonic development of the ENS can induce multiple pathologies in animal models and humans.

Case presentation: The present case was a female the fifth born in a litter of 5 puppies. At about 2-3 weeks of age, she suffered from abdominal distension, pain, and constipation. At approximately $8-10$ weeks of age, the puppy started to vomit abundantly, and the regurgitated food appeared undigested. Progressive abdominal distention was observed, with quite visible peristaltic movements and more frequent vomiting episodes. The abdominal radiographs, based on AP and side projections, revealed an enlargement of the abdominal diameter and an increased width in the epigastric region. At 12 weeks of age, exploratory surgery revealed a stenotic segment in the jejunum, followed by a small transition zone and then a significantly reduced diameter. Immunohistochemical examinations were performed using antibodies against calretinin, S-100 protein, CD56, neuron specific enolase (NSE) and synaptophysin, which are the biological markers for diagnosing HSCR.

Conclusion: A reduced number of ganglion cells (1-3 cells per ganglion) were found. There was no specific staining pattern for many of these; while for others, the pattern was compatible with HSCR. Surgical intervention to remove the stenotic section prolonged the life of the puppy for 13 years. Extremely rare pathologies such as that discussed herein should be studied to understand the pathophysiology and be able to diagnose small species in veterinary medicine in a timely fashion. To our knowledge, this is the first report of congenital intestinal stenosis and Hirschprung's disease in a newborn puppy.
\end{abstract}

Keywords: Congenital intestinal stenosis, Enteric nervous system, Ganglion cells, Hirschsprung's disease

Correspondence: angelica.moralesm@incmnsz.mx

Department of Reproductive Biology, National Institute of Medical Sciences and Nutrition Salvador Zubirán, Avenue. Vasco de Quiroga 15 Col. Belisario Domínguez, Section XVI, Tlalpan, 14080 México City, Mexico

(c) The Author(s). 2019 Open Access This article is distributed under the terms of the Creative Commons Attribution 4.0 International License (http://creativecommons.org/licenses/by/4.0/), which permits unrestricted use, distribution, and reproduction in any medium, provided you give appropriate credit to the original author(s) and the source, provide a link to the Creative Commons license, and indicate if changes were made. The Creative Commons Public Domain Dedication waiver (http://creativecommons.org/publicdomain/zero/1.0/) applies to the data made available in this article, unless otherwise stated. 


\section{Background}

The embryonic development of the enteric nervous system (ENS) is a complex process that begins with the migration of neural crest cells, followed by their proliferation and differentiation in the wall of the gastrointestinal tract. There are key points during this process in which cells must undergo certain transformations for the attainment of a functional ENS.

The coordinated action of neural crest cells is critical for the development and functioning of the intestinal microenvironment $[1,2]$. Some studies have demonstrated that a specific number of cells is required for the migration through the intestinal mesenchyme to begin. This migration occurs in the craniocaudal direction in response to diffusible molecules in cell-cell interactions.

The expression of transcription factors induces cell arrest, proliferation, and differentiation for neuronal and/ or glial phenotypes [3-5]. During this process, the vital function of motility develops in the gastro-intestinal tract. Gut motility is a complex process mediated by the interaction between intestinal smooth muscle, interstitial cells of Cajal, and a diverse range of neuronal phenotypes (characterized by neurotransmitters) in the ENS. All these cells are essential for generating the two main types of contractions in the gut: segmentation and peristaltic waves. These two mechanisms occur in the absence of extrinsic innervation and require intact submucous (Meissner) and myenteric (Auerbach) nerve plexus along the gastrointestinal tract $[6,7]$. In large animal species, there is a third plexus called Henle's or Schabadasch's plexus, which is adjacent to the luminal side of the circular muscle coat. According to the species, these plexuses differ in number, shape and size of ganglia, number and size of neurons and number and diameter of nerve fibers [8-12].

Hirschsprung's disease (HSCR) is a congenital disorder involving the absence of ganglion cells in the submucous and myenteric nerve plexus, which leads to an obstruction of the gastrointestinal tract. The first presentation of HSCR symptoms is attributed to a Danish pediatrician, Harald Hirschsprung, MD., (1830-1916) [13]. Nevertheless, similar symptoms were reported by Italian physician Domenico Battini, who did the follow-up on a case of severe constipation ten years previously [14].

Today, more than a century after the death of Harald Hirschsprung, significant progress has been made in characterizing the molecular processes involved in the pathogenesis of HSCR $[15,16]$. The disease is located in the last portion of the gastrointestinal tract (the rectum and sigmoid colon) in $80 \%$ of cases, while extending to other colon segments in $20 \%$ of cases [17-19]. HSCR is extremely rare in the small intestine, as a manifestation of total enteric aganglionosis is almost impossible. The report on "skip segment" Hirschsprung's disease (SSHD) describes a zone of aganglionosis within the normally ganglionated intestine. Other variants of intestinal sections from patients with HSCR-like symptoms have sometimes evidenced hypoganglionosis (a decrease in the number of ganglion cells in both plexus) or "immature" neuronal cells. The pathogenesis of these presentations cannot be explained embryologically [20-22].

Multiple reports have associated HSCR with malformations that occur in polygenic disorders [23, 24], such as Down syndrome [25], Waardenburg syndrome [26], Bardet-Biedl syndrome, gastrointestinal malformations (Meckel's diverticulum, colonic atresia and anorectal defects), and congenital heart disease (septal defects or ductus arteriosus) [27].

Genetic studies have suggested that autosomal dominant Mendelian inheritance with a mutation in RET on chromosome 10 (locus at long arm 10q11.2q21.2), now referred to as $\boldsymbol{H S C R} \mathbf{1}$, has a $250-\mathrm{kb}$ DNA interval containing the RET proto-oncogene. This mutation is responsible for approximately $40 \%$ of the cases of Hirschsprung's disease [28].

RET is a cell-surface protein possessing an extracellular ligand-binding domain, a single hydrophobic transmembrane region, and an intracytoplasmic tyrosine kinase domain. It plays a crucial role during the development of the excretory system and the ENS [29, 30]. Recently a second HSCR2 locus was identified on chromosome 13 (the deletion of 13q), which is linked to congenital anomalies [31]. Although mutations of the RET tyrosine kinase gene are still the only known cause of the disorder, there are reports of at least 12 genes that determine the final phenotypic expression of the pathogenesis. These genes include the endothelin converting enzyme ECE-1(1p36.1) [32], the glial-cell-line-derived neurotrophic factor GDNF (5q1213.1) $[33,34]$, endothelin receptors type $B$ or EDNRB (13q22) [35], NTN (19p13.3) [36], endothelin 3 EDN3 (20q13.2-13.3) [37], and the gene encoding the Sry-related transcription factor SOX10 (22q13.1) [38]. Analysis of the afore mentioned gene products in experimental animal models and cell cultures has led to increasing clarity about the signaling pathways involved during specific embryonic stages that direct the spatial arrangements and differentiation of enteric cells derived from the neural crest [39-43].

Recent studies show growth factors as key to the development of Hirschsprung's disease, these being fundamental for the survival, differentiation, and function of enteric neurons and glia during fetal gut development $[44,45]$. Among such growth factors are brain-derived neurotrophic factor (BDNF), nerve growth factor (NGF) and neurotrophin-3 (NT-3) [46-48].

Growth factors are ligands for the tyrosine kinase family of receptors (RTKs), encoded by Trk proto-oncogenes. These ligands and receptors are both 
essential components for interactions between neurotrophins and neuronal cells.

Little is known about the relation of Hirschsprung's disease to other congenital intestinal malformations, such as stenosis or atresia. Congenital malformations encompass a wide variety of alterations during fetal development. In 1955, Louw et al. reported the possibility that an occlusion in the blood supply or an episode of ischemia triggers alterations in gut developmental $[49,50]$. Experiments using animal models have demonstrated that a permanent occlusion in the blood supply can be one of the causes of atresia, stenosis and similar pathologies [51].

We herein present a clinical case of a newborn pup (Yorkshire Terrier) which was first taken to the veterinarian due to vomiting, enormous distension of the abdomen and constipation. The initial diagnosis was difficult, since this is an extraordinarily rare disease in veterinary medicine. However, the clinical data was similar to that found with HSCR in humans or congenital enteric neuropathies.

\section{Case presentation}

The dog was the female the fifth born in a litter of 5 puppies. Compared to her siblings, she exhibited the smallest size and lowest weight from birth. At about 23 weeks of age, she suffered from abdominal distension, pain, and constipation. The veterinarian recommended rectal stimulation and cisapride (prepusid) $0.5 \mathrm{ml}$ every 8 hours for 2 days. With great effort, the puppy defecated once a day after stimulation, and her stools had normal characteristics. At approximately $8-10$ weeks of age, she began a diet of semisolid food consisting of small portions eaten 3-5 times a day, which caused her to start vomiting abundantly.

The regurgitated food appeared undigested. Blood tests, stool analysis, and liver function tests were normal, giving no clues for a diagnosis. Anti-parasitic treatment was initiated but did not improve her symptomatology.
Multiple diets were implemented, including soymilk and pancreatic enzymes prescribed for supposed lactose intolerance or pancreatic insufficiency.

Progressive abdominal distention was observed (Fig. 1a), with quite visible peristaltic movements and more frequent vomiting episodes. During the clinical examination, the second row of upper and lower teeth were noted (Fig. 1b). Different veterinarians were consulted, and one suggested a probable alteration in intestinal motility. Regulators of peristalsis (metoclopramide, dimeticone, and lactulose) were prescribed. On some occasions, third generation quinolones were administered to treat bacteremia. None of the treatments or schemes led to an improvement in the dog, resulting in a severe deterioration of her general condition accompanied by fever.

The abdominal radiographs, based on AP and side projections, revealed an enlargement of the abdominal diameter with the presence of gas in the intestinal wings, and an increased diameter in the epigastric region (Fig. 2a and b). Abdominal ultrasonography on distinct dates evidenced dilated bowel loops with a great amount of echogenic content, a thin wall in the intestinal wings, and free liquid in the intra-abdominal cavity (Fig. 3a, b and c and Additonal file 1). The liver, biliary ducts, and kidneys had normal characteristics.

After multiple studies and many visits to veterinarians, there was a recommendation of exploratory surgery, which was performed when the puppy was about 12 weeks old. During the examination of the abdomen, a stenotic segment of approximately $12 \mathrm{~cm}$ was identified in the jejunum, followed by a small transition zone and then a significantly reduced diameter (Fig. 4a). Resection of this segment and surgical management of a jejunoileonstomy was carried out (Fig. 4b and c).

The circumference of the stenotic segment was approximately $5 \mathrm{~mm}$ and of the dilated proximal extreme about 3 $\mathrm{cm}$ (Fig. 4d, and Fig. 5a). The open segment shows fibrotic

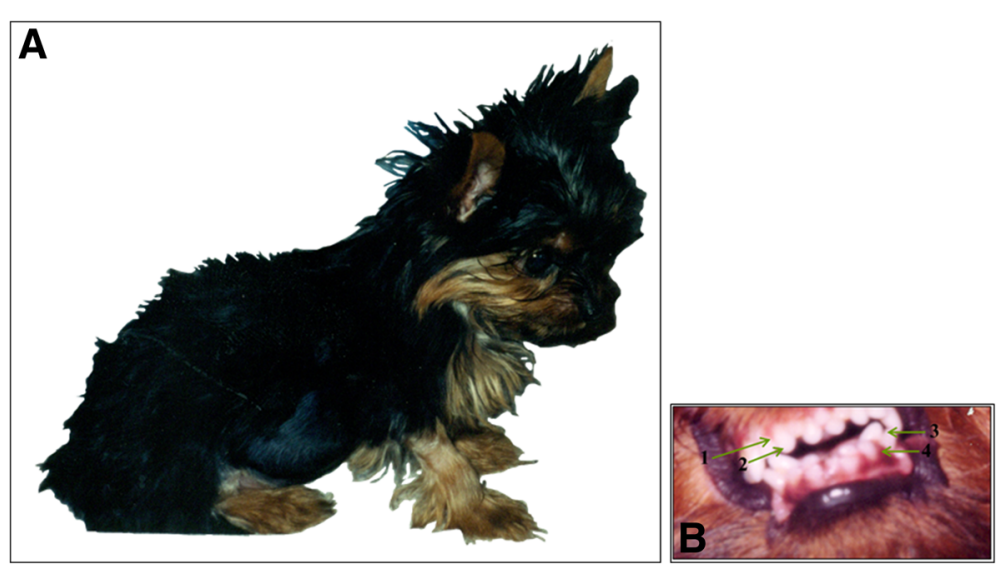

Fig. 1 Photograph of the puppy under study at approximately 10 weeks of age, with an enormous abdominal distension (a) and a second row of teeth $(\mathbf{b})$ 

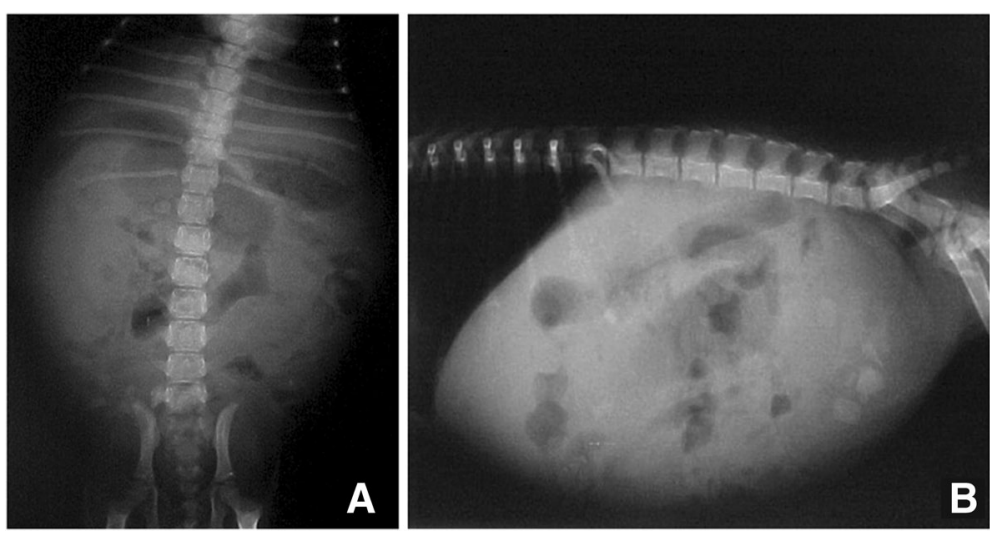

Fig. 2 Radiological features of abdominal distension, showing an increase in abdominal diameter and the presence of gas in the intestinal loops, as can be appreciated in the anteroposterior view (a) and lateral view (b)

tissue that occludes this small transition zone (Fig. 5b). No other abdominal injury was present. The abdominal fascia was closed with 3-0 polyglactin and the skin with 3-0 nylon suture.

The postoperative period was uneventful, and the puppy was discharged on day four post-surgery without complications. She was given a soft diet, and her weight subsequently increased. Her feces content took on a healthy form. A post-surgical ultrasound revealed bowel loops with a diminished diameter and normal peristaltic movements (Fig. 6 and Additional file 2). The puppy lived the next 13 years without digestive problems.

We hypothesized that abdominal distention, vomiting, and constipation in the early stages of the life of the dog pup could evidence a disorder similar to human disease.
Thus, the symptomatology of the disorder was compared to pediatric diseases of the digestive tract. The specific combination of clinical signs and symptoms, in this case, led to a tentative diagnosis of Hirschsprung's disease. However, the discovery of jejunum stenosis made the diagnosis of HSCR less likely. Stenosis is an extremely rare congenital condition that is usually located in the small intestine, as presently found. It is generally resolved with a relatively safe surgery. Accordingly, a primary anastomosis was herein performed with a maximal diameter variance of 3:1 (proximal: distal) [52]. A small surgically resected fragment was obtained and embedded in a single block of paraffin, which was sliced and placed on slides (Fig. 5). H\&E staining was used, since it is the diagnostic method of choice for identifying ganglion cells in both plexus [53].
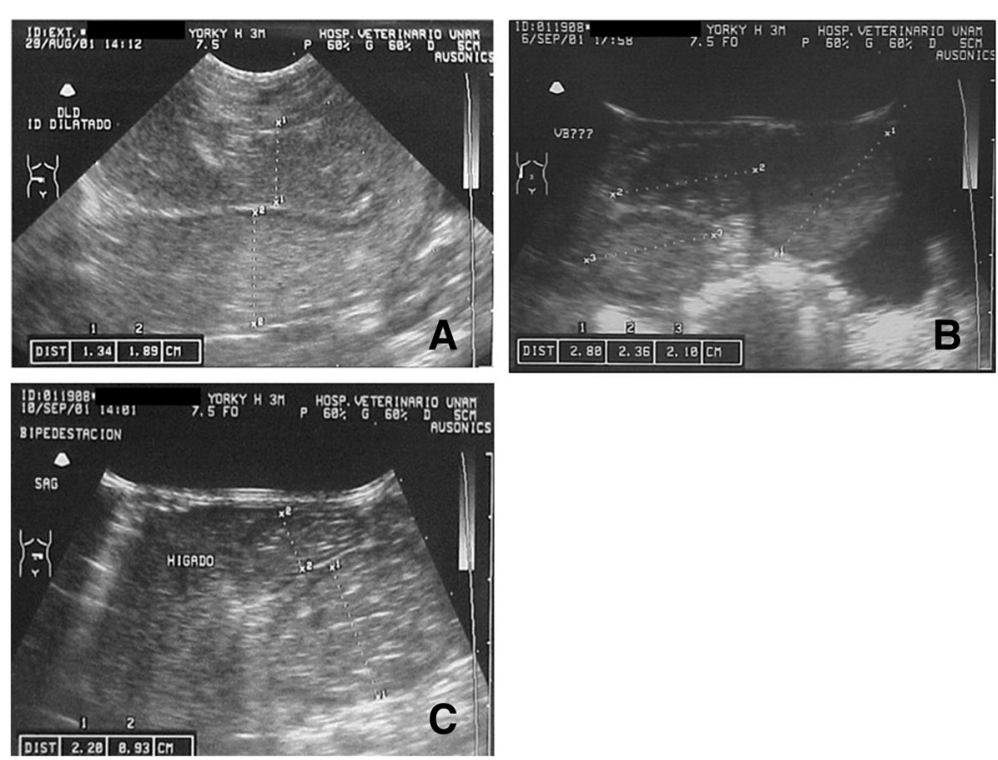

Fig. 3 The abdominal ultrasound reveals an increase in the diameter of the small intestine, from 1.34 to $2.20 \mathrm{~cm}$. There is enhanced echogenicity, the presence of liquid and gas, and a thin wall in the loops of the intestine (a-b). The liver and gallbladder are within normal limits (c) 

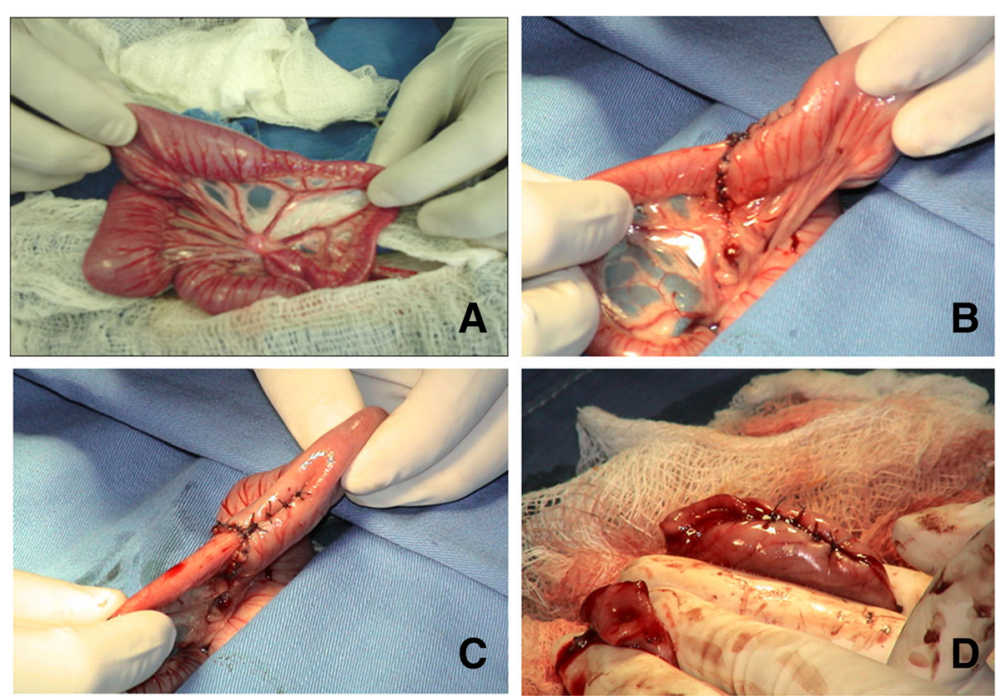

Fig. 4 Photographs taken during surgery illustrate a segment of approximately $12 \mathrm{~cm}$ of the intestine, corresponding macroscopically to the jejunum. A reduction in diameter can be observed before the segment of stenosis (a). The subsequent images demonstrate the elimination of this segment, and then the technique used for the reduction of the hypertrophied segment and the joining of the two ends of the intestine (bd). The proximal diameter had a circumference of $0.5 \mathrm{~cm}$, while the distal side measured $3-4 \mathrm{~cm}$

Whereas histopathological analysis revealed mucosa without alterations, the submucosa expanded in varying degrees through fibrous connective tissue, in the transverse and longitudinal muscular layer, and in the adipose tissue adjacent to the serosa.
Additionally, there was neoformation of blood vessels and edema (Fig. 7a and b). Degenerative ganglion was mild to moderate in both plexus. The ganglion cells had an oval nucleus with fine granular or euchromatin (degeneration) and eosinophilic cytoplasm (Fig. 7c and d).
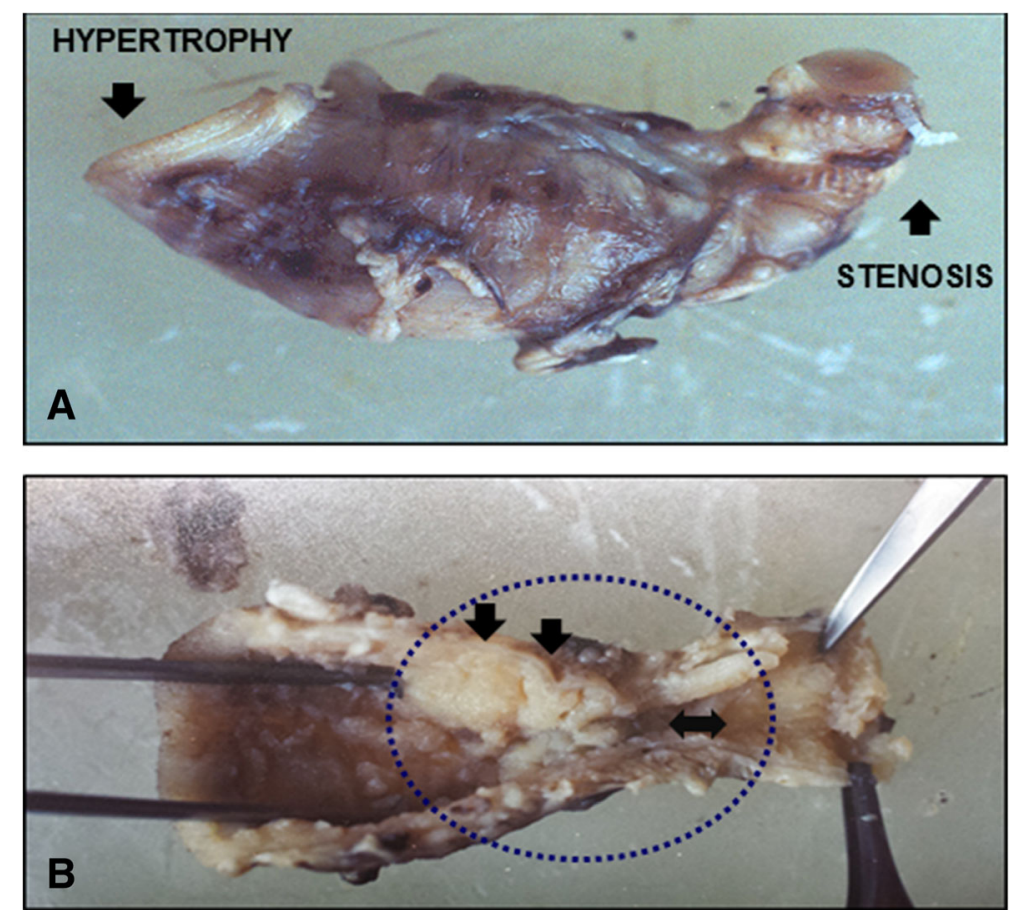

Fig. 5 A fragment of the small intestine obtained during surgery (a). Upon opening this segment, it was found that fibrotic tissue occupied a considerable part of the intestinal lumen (without completely occluding it) and was present in the transition zone (b) 

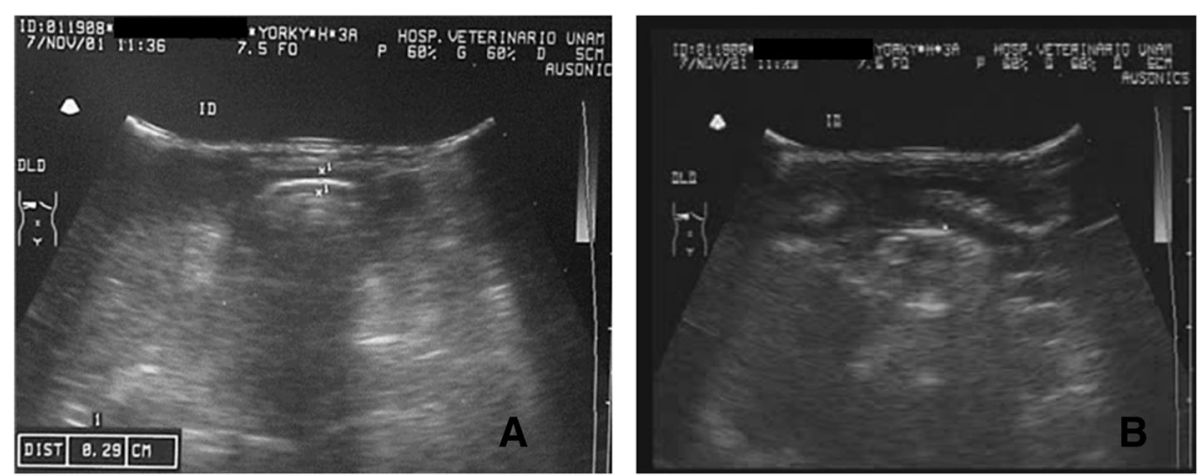

Fig. 6 The ultrasound image of the real size of the intestine reveals a greatly reduced diameter $(0.29 \mathrm{~cm})$ after surgery $(\mathbf{a})$ compared to before surgery. In the video, normal intestinal movements can be appreciated (b)

To confirm this observation, various pathologists were consulted. After making multiple cuts, all the specialists coincided with the finding of ganglion cells along the fragment (hypertrophy-fragment, transition zone, and stenotic fragment), and that these had the previously described morphological characteristics. The method used for immunohistochemistry (IHC) has been previously described in detail by Morales et al. [54]. Calretinin, S-100 protein and CD56 antibodies have been used for studies in different animal species including dogs $[55,56]$. Cross reactivity of antibodies among different species is a standard practice for the selection of other neural immunomarkers [57-59].

Briefly, a small fragment of stenosed intestine was fixed in $4 \% w / v$ formaldehyde in phosphate-buffered saline
(PBS), for $24 \mathrm{~h}$. Paraffin-embedded tissue sections $(5-\mu \mathrm{M}$ thickness) were mounted on glass slides (DAKO Corp., Santa Barbara, CA, USA), the sections were dewaxed in xylene (Sigma-Aldrich, Saint Louis, MO, USA) and rehydrated in graded ethanol solutions. Histopathological evaluation of some sections was stained with H\&E (Sigma-Aldrich, Saint Louis, MO, USA). Slides were heated by microwave radiation for $10 \mathrm{~min}$ in $0.01 \mathrm{M}$ citrate buffer (pH 6.0) for antigen retrieval. The activity of endogenous peroxidase was blocked with $0.3 \% \mathrm{H}_{2} \mathrm{O}_{2}$ /methanol at room temperature for $30 \mathrm{~min}$. To prevent nonspecific antibody binding, sections were preincubated with protein blocking buffer diluted in PBS/bovine serum albumin (BSA; 1\%; Sigma-Aldrich) for $60 \mathrm{~min}$. Slides were then incubated with respective primary antibodies to anti-
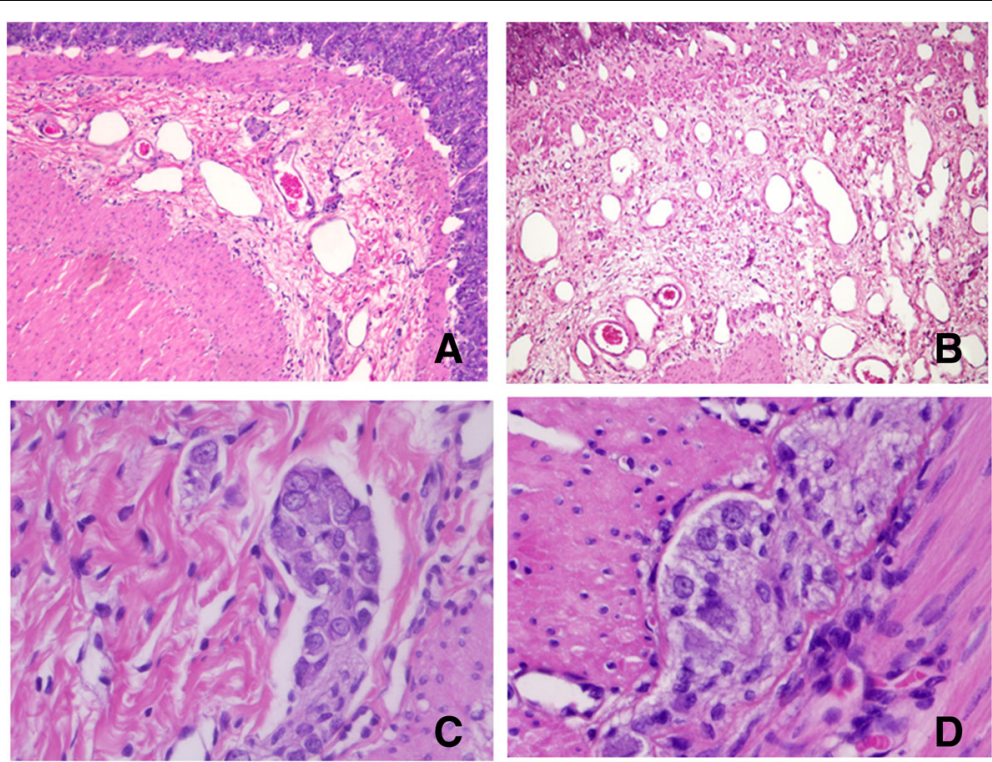

Fig. 7 Histological aspect of small intestine stained with H\&E. Panel $\mathbf{a}$ and $\mathbf{b}$ show changes in the submucous, such as fibrous connective tissue, edema, inflammation and angiogenesis. Degenerative changes of ganglion cells can be appreciated in both plexus (panels $\mathbf{c}$ and $\mathbf{d}$ ) Magnification, $\times 10$ (panels a-b) and $\times 40$ (panels c-d) 
Calretinin (clone: EP1798, dilution 1:300), anti-CD56 (clone 123C3.D5, dilution 1:200), anti-S100 protein (clone: 4C4.9, dilution 1:200), (BioSB, Santa Barbara, CA, USA), anti-NSE (ab79757, dilution 1:200), (Abcam, Burlingame, CA, USA) and anti-Synaptophysin (clone SY38, dilution 1:100), (DAKO Corp., Santa Barbara, CA, USA), overnight at $4{ }^{\circ} \mathrm{C}$. Subsequently, the slides were washes with PBS for 5 min each, the primary antibody was detected with the appropriate secondary antibody (Mouse/Rabbit-ImmunoDetector-HRP Cat. BSB0003-BioSB) at 1:100 dilution for $60 \mathrm{~min}$ at $37^{\circ} \mathrm{C}$. The sections were washed for $5 \mathrm{~min}$, and incubated using 3, 3'-diaminobenzidine tetrahydrochlo-

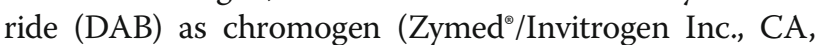
USA). Finally, the slides were rinsed in distilled water and nuclear counterstaining with Mayer's hematoxylin (MHS-1, Sigma-Aldrich Co., St. Louis, MO, USA). The sections were mounted and coverslipped with a synthetic mounting medium (Entellan; Merck, Darmstadt, Germany; OB046327). Photographs were taken on a Nikon-Eclipse 80i microscope coupled to a Nikon digital sight camera (Melville, NYC, USA). In each case, negative controls without the primary antibody were included (data not shown). The results of the IHC shown herein represent the general pattern of staining evidenced in the respective areas. Calretinin did not positively stain ganglion cells, observe positivity to peripheral (neurons, Schwann cells, and axons) in the myenteric plexus (Fig. 8). The reactivity of the ganglion cells to S-100 protein was negative in both plexus (Fig. 9). The staining pattern for CD56 was moderately immunopositive in glial cells throughout the submucous and in the myenteric plexus, but negative in ganglion cells (Fig. 10). Two new markers, NSE and synaptophysin, have been extensively used for diagnosis of Hirschsprung's disease. The NSE staining was herein found to be strongly positive in the epithelium as well as the nerve cells and nerve fibers. Intense intracytoplasmic dysfunction was exhibited in the ganglion cells of the myenteric plexus. (Fig. 11). Compared to the ganglion cells, many neurons exhibited a stronger signal for NSE during embryonic development and later stages $[60,61]$. For synaptophysin, on the other hand, staining was unspecific around glia cells (Fig. 12). Unfortunately, the complete stent fragment could not be obtained for this assay.

\section{Discussion and conclusions}

Studies that explore the possible similarity of pathogenesis in distinct species are scarce. Such reports give comparisons of human diseases to those of horses, mice, calves and others domestic species like cats [62-64]. Regarding similarities in the development of the ENS for distinct species, many aspects coincide for all vertebrate classes, including mammals, birds, reptiles, amphibians, and fish [65-67]. Indeed, species-specific differences are minimal. Various mutations have been characterized in animal models and humans. It is generally accepted that genetic mutations in some animal models lead to developmental defects in neural crest cell migration, differentiation and/or survival.

A careful search of the literature was conducted in respect to the anomalies associated with double row of teeth. There are few descriptions of such a condition in the literature that demonstrate a similarity between species $[68,69]$. Even though genetic tests for identifying
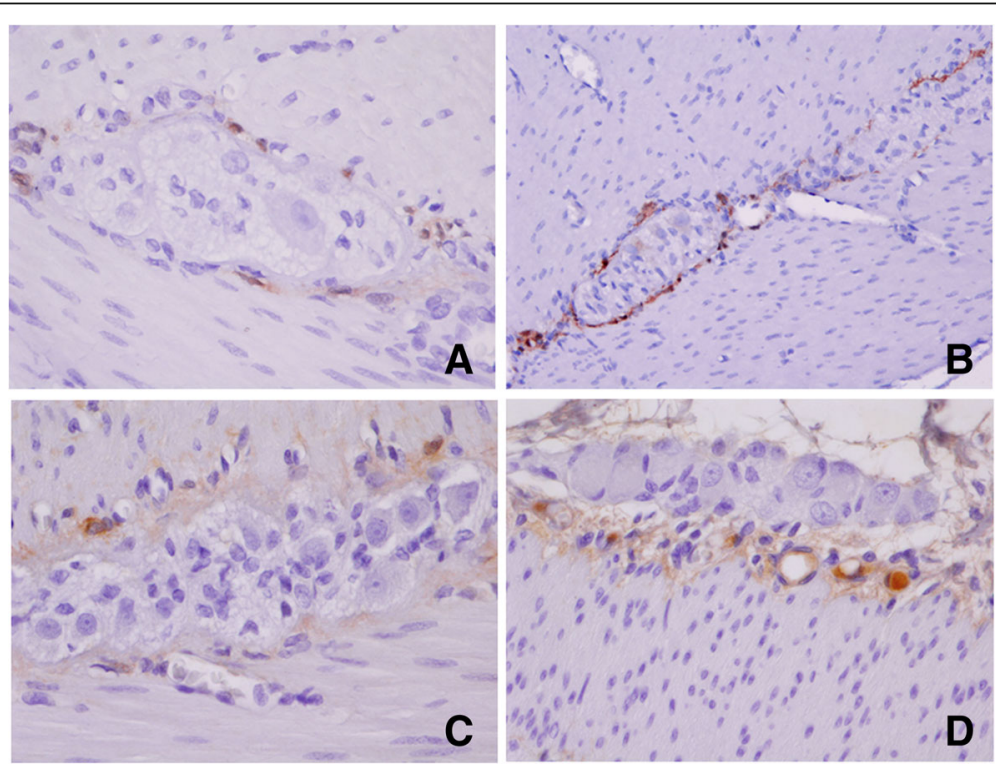

Fig. 8 Representative microphotograph showing a total absence of calretinin staining in ganglion cells. In every panel, we can observe positivity to peripheral neurones, Schwann cells, and axons in the myenteric plexus. Magnification, $\times 40$ (panels $\mathbf{a}$, $\mathbf{c}$-d) and $\times 10$ (panel b) 


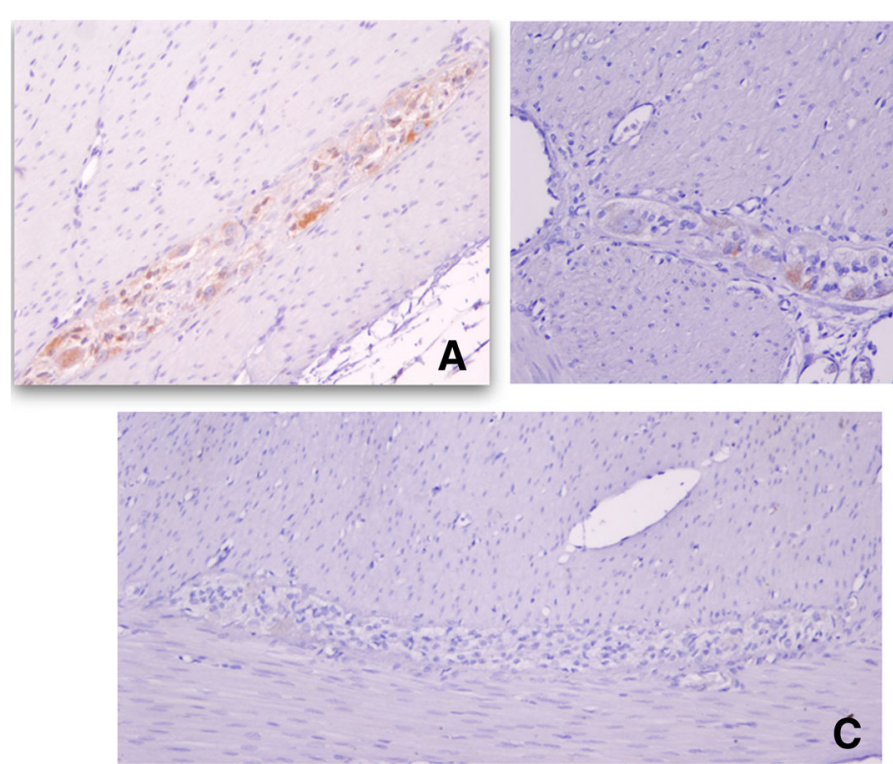

Fig. 9 Representative light micrographs for S-100 protein. Panels $\mathbf{a}$ and $\mathbf{b}$ show a moderate staining in Schwann cells in the myenteric plexus. A total absence of ganglion cells is depicted in panel $\mathbf{c}$. Magnification, $\times 20$ (panels $\mathbf{a}, \mathbf{b}$-c $\mathbf{c}$ )

mutated chromosomes are commercially available for humans and horses, this is not the case for other species. Unfortunately, no other information is available because genetic studies in veterinary medicine are sporadic.

The present case report has some limitations that significantly reduce the certainty of a parallel between this extremely rare disease in humans and animals. Although the dog pup was examined from the time of birth, little control was exercised over some clinical variables, and the surgical intervention was not based on a thorough diagnosis.
Additionally, only a small tissue fragment could be obtained and processed. To standardize identification and counting of myenteric neurons, the criteria published by Swaminathan et al., 2010 was applied [70]. In the hypertrophic and stenotic segments, twenty random fields of $160 \mu^{2}$ each were examined in the hematoxylin and eosin (H\&E)-stained sections, as well as for those immunostained for calretinin, S-100 protein, CD56, neuron specific enolase (NSE) and synaptophysin for a total of $19.2 \mathrm{~mm}^{2}$ of tissue studied. Each observation area was photographed
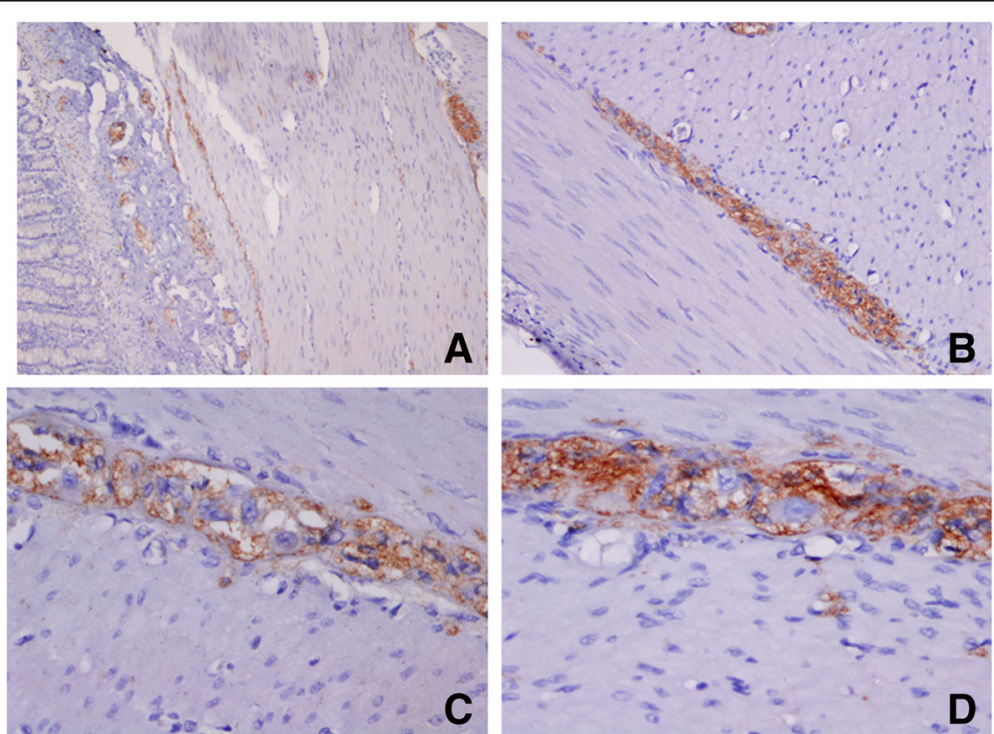

Fig. 10 Immunohistochemical analysis of CD56. Panel (a) show images with positive immunostaining in both plexus. In panel (b), an intense staining is present in the cytoplasm of glial cells. Panels $(\mathbf{c}-\mathbf{d})$, show images of a reduced number of ganglion cells in the myenteric plexus. Magnification, $\times 10($ panel a), $\times 20($ panel b) and $\times 40$ (panels $\mathbf{c}-\mathbf{d})$ 

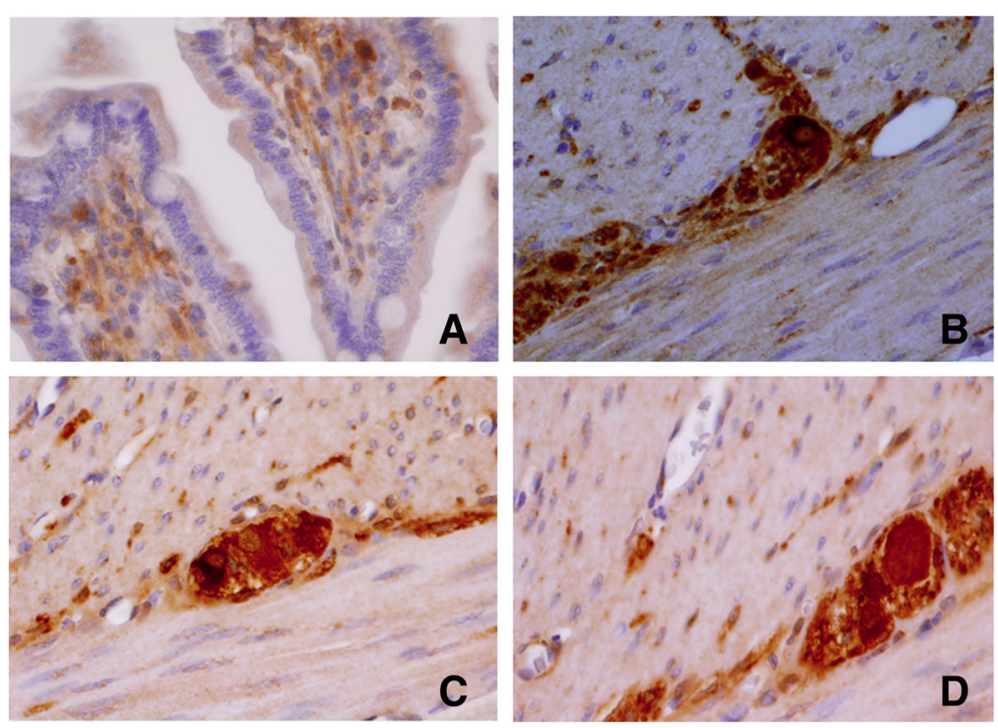

Fig. 11 The NSE shows a strong intracytoplasmic positivity in neuroendocrine cells of the intestinal mucosa (panel a). In panels $\mathbf{b}$, $\mathbf{c}$ and $\mathbf{d}$, ganglion cells display intense cytoplasmic and nuclear staining in the myenteric plexus. Magnification, $\times 40$ (panels $\mathbf{a}-\mathbf{b}$ and $\mathbf{c}-\mathbf{d}$ )

using an Olympus BX51 light microscope and the images were analyzed using ImageJ software (Image-Pro Plus Version 3.1; Media Cybernetics, Inc.). The results revealed that in the stenotic segment the average number of cells was $20.21 \pm 7.7$ vs $40.12 \pm 10.57$ found in the hypertrophic segment, representing a $50 \%$ reduction in the density of ganglion cells. The independent-sample Student $t$ test was used to compare differences between the two segments. The cumulative probability showed a significant difference $(P=0.021)$. The histological findings of stenosis indicate a relationship with HSCR, because the microscopic analysis showed a marked reduction of ganglion cells in the tissue portion removed.

It is currently recognized that this disorder takes on distinct forms, although clinicians and pathologists consulted in veterinary medicine know little about Hirschsprung's disease. The pattern of staining for most of the markers (e.g., calretinin, S-100 protein and CD56) suggests a diagnosis of HSCR [71, 72]. Immunostaining was negative for most specific markers for HSCR. However, the ganglion cells detected may have been immature and/or non-functional. It can be assumed that ganglion
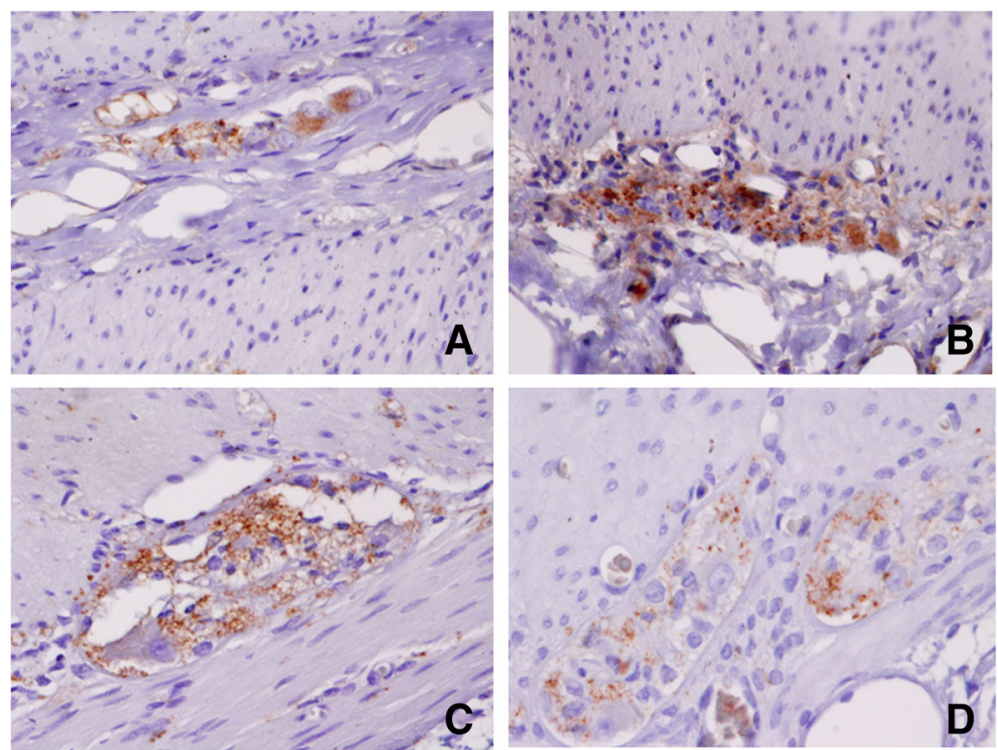

Fig. 12 Synaptophsin (SYN) labeling. Images in panels a-b show moderate immunolabeling in cells located inside the ganglion. However, the ganglion cells were not immunolabeled panels as shown in panels c-d. Magnification, $\times 20$ (panel b) and ×40 (panels a, c-d) 
cells were absent along the fragment of stenosis. Contrarily, these cells were present in the anastomosis at the level of the ileum, allowing for the normal functioning of the small intestine.

Fortunately, surgical resection for removal of the aganglionic bowel and reconstruction of the intestinal tract is now possible because of recent technological advances. Consequently, mortality due to a gastrointestinal obstruction can be avoided in animal models and humans. Among the acute complications of this disease, if untreated, is rapid exhaustion induced by the inability of the organism to nourish itself. The consequence could be toxicity and death.

In the field of veterinary medicine, there are few publications of clinical cases involving pets born with rare pathologies, which owes itself to the poor prognosis and the high cost of treatment. Hence, most pet owners choose to euthanize. Hirschsprung's disease has complex pathogenesis that is not yet completely understood. Further basic and clinical research is necessary to elucidate the relationship between stenosis and HSCR and explore the similarity of the pathological mechanisms in animal models and humans.

\section{Additional files}

Additional file 1: Abdominal ultrasound performed before surgery. An increase in small intestine movements are observed. (WMV $1950 \mathrm{~kb}$ )

Additional file 2: Abdominal ultrasound performed after surgery. Restoration of normal peristalsis. (WMV $1950 \mathrm{~kb}$ )

\begin{abstract}
Abbreviations
BDNF: Brain-derived neurotrophic factor; CD56: Neural cell adhesion molecule; DAB: 3,3'- diaminobenzidine tetrahydrochloride hydrate; ECE1: endothelin converting enzyme 1; EDN3: Endothelin 3; EDNRB: Endothelin receptor type B; ENS: Enteric nervous system; GDNF: Glial-cell-line-derived neurotrophic factor; H\&E: Hematoxylin and eosin; HSCR: Hirschsprung's disease; HSCR1: Hirschsprung disease type 1; HSCR2: Hirschsprung disease type 2; IHC: Immunohistochemistry; MHS1: Hematoxylin solution, Mayer's; NGF: Nerve growth factor; NSE: Neuron specific enolase; NT-3: Neurotrophin3; RET proto-oncogene: Encodes a receptor tyrosine kinase; RTKs: Receptor tyrosine kinases; S-100: Family of low-molecular-weight proteins; SOX10: Transcription factor SOX-10 is a protein encoded by the SOX10 gene; SSHD: Skip segment-Hirschsprung's disease; SYN: Synaptophysin
\end{abstract}

\begin{abstract}
Acknowledgements
The author is grateful to MVZ. Jesus Paredes and the staff in the operating room for their assistance in the procurement of a tissue sample, and to MVZ. Rosa Elena Mendez for the cabinet material and video (Department of Small Species, College of Veterinary Medicine, National Autonomous University of México, México City, México). My thanks to MVZ. Javier I. Camacho (Veterinary Diagnostics Alhambra), Dr. Carlos Serrano (Department of Pathology, Children's Hospital of México "Federico Gomez", México City, México) and Dr. Fredy Chable Montero (Department of Pathology, Hospital Médica Sur), for his expert pathology assistance. I wish to thank Bruce Allan Larsen for proofreading the final version of the manuscript. To the memory of Tammy, the puppy that was the study case of this article.
\end{abstract}

\section{Funding}

No dedicated funding for this study.

\section{Availability of data and materials}

Our findings are contained within the manuscript.

\section{Authors' contributions}

AMM analyzed and interpreted the results and drafted the final manuscript. The author read and approved the final manuscript.

Ethics approval and consent to participate

Not applicable.

\section{Consent for publication}

Consent granted by the owner.

\section{Competing interests}

The author declare that there are no competing interests in the present study, either in the use of material or techniques.

\section{Publisher's Note}

Springer Nature remains neutral with regard to jurisdictional claims in published maps and institutional affiliations.

Received: 3 November 2017 Accepted: 8 February 2019

Published online: 13 March 2019

\section{References}

1. Nagy N, Goldstein AM. Enteric nervous system development: a crest cell's journey from neural tube to colon. Semin Cell Dev Biol. 2017;66:94-106.

2. Furness JB. Integrated neural and endocrine control of gastrointestinal function. Adv Exp Med Biol. 2016;891:159-73.

3. Charrier B, Pilon N. Toward a better understanding of enteric gliogenesis. Neurogenesis (Austin). 2017;4(1):e1293958.

4. Hao MM, Young HM. Development of enteric neuron diversity. J Cell Mol Med. 2009;13:1193-210.

5. Furness JB. Types of neurons in the enteric nervous system. J Auton Nerv Syst. 2000:81:87-96.

6. Boeckxstaens GE. Understanding and controlling the enteric nervous system. Best Pract Res Clin Gastroenterol. 2002;16:1013-23.

7. Sang Q, Young HM. Chemical coding of neurons in the myenteric plexus and external muscle of the small and large intestine of the mouse. Cell Tissue Res. 1996;284:39-53.

8. Hansen MB. The enteric nervous system I: organisation and classification. Pharmacol Toxicol. 2003:92:105-13.

9. Timmermans JP, Hens J, Adriaensen D. Outer submucous plexus: an intrinsic nerve network involved in both secretory and motility processes in the intestine of large mammals and humans. Anat Rec. 2001;262:71-8.

10. Timmermans JP, Scheuermann DW, Stach W, et al. Functional morphology of the enteric nervous system with special reference to large mammals. Eur J Morphol. 1992;30:113-22.

11. Balemba OB, Hay-Schmidt A, Assey RJ, et al. An immunohistochemical study of the organization of ganglia and nerve fibres in the mucosa of the porcine intestine. Anat Histol Embryol. 2002;31:237-46.

12. Balemba OB, Mbassa GK, Semuguruka WD, et al. The topography, architecture and structure of the enteric nervous system in the jejunum and ileum of cattle. J Anat. 1999;195:1-9.

13. Hirschsprung $\mathrm{H}$. Stuhltragheit Neugeborener in Folge von Dilatation und Hypertrophie des Colons. Jhrb f Kinderh. 1888;27:1-7.

14. Fiori MG. Domenico Battini and his description of congenital megacolon: a detailed case report one century before Hirschsprung. J Peripher Nerv Syst. 1998:3:197-206

15. Cass D. Hirschsprung's disease: an historical review. Prog Pediatr Surg. 1986; 20:199-214.

16. Sergi C. Hirschsprung's disease: historical notes and pathological diagnosis on the occasion of the 100(th) anniversary of Dr. Harald Hirschsprung's death. World J Clin Pediatr. 2015:4:120-5.

17. Rayhorn NJ, Ingebo KR. Aganglionosis of the small intestine: a rare form of Hirschsprung's disease. Gastroenterol Nurs. 1999;22:164-6.

18. Badizadegan $K$, Thomas AR, Nagy N, et al. Presence of intramucosal neuroglial cells in normal and aganglionic human colon. Am J Physiol Gastrointest Liver Physiol. 2014;307:G1002-12.

19. Morris G, Kennedy A Jr, Cochran W. Small bowel congenital anomalies: a Review and Update. Curr Gastroenterol Rep. 2016;18:16. 
20. Erten EE, Çavuşoğlu YH, Arda N, et al. A rare case of multiple skip segment Hirschsprung's disease in the ileum and colon. Pediatr Surg Int. 2014;30: 349-51.

21. Doi T, O'Donnell AM, McDermott M, et al. Skip segment Hirschsprung's disease: a rare phenomenon. Pediatr Surg Int. 2011;27:787-9.

22. Yunis E, Sieber WK, Akers DR. Does zonal aganglionosis really exist? Report of a rare variety of Hirschsprung's disease and review of the literature. Pediatr Pathol. 1983;1:33-49.

23. Tam PK, Garcia-Barceló M. Genetic basis of Hirschsprung's disease. Pediatr Surg Int. 2009;25:543-58.

24. Borrego S, Ruiz-Ferrer M, Fernández RM, et al. Hirschsprung's disease as a model of complex genetic etiology. Histol Histopathol. 2013;28:1117-36.

25. Arnold S, Pelet A, Amiel J, et al. Interaction between a chromosome 10 RET enhancer and chromosome 21 in the Down syndrome-Hirschsprung disease association. Hum Mutat. 2009;30:771-5.

26. Shim WK, Derieg M, Powell BR, et al. Near-total intestinal aganglionosis in the Waardenburg-Shah syndrome. J Pediatr Surg. 1999;34:1853-5.

27. Duess JW, Puri P. Syndromic Hirschsprung's disease and associated congenital heart disease: a systematic review. Pediatr Surg Int. 2015;31: 781-5.

28. Fewtrell MS, Tam PK, Thomson AH, et al. Hirschsprung's disease associated with a deletion of chromosome 10 (q11.2q21.2): a further link with the neurocristopathies? J Med Genet. 1994;31:325-7.

29. Edery P, Lyonnet S, Mulligan LM, et al. Mutations of the RET protooncogene in Hirschsprung's disease. Nature. 1994;367:378-80.

30. Bordeaux MC, Forcet $C$, Granger $L$, et al. The RET proto-oncogene induces apoptosis: a novel mechanism for Hirschsprung disease. EMBO J. 2000;19: 4056-63.

31. Shanske A, Ferreira JC, Leonard JC, et al. Hirschsprung disease in an infant with a contiguous gene syndrome of chromosome 13. Am J Med Genet. 2001:102:231-6

32. Hofstra RM, Valdenaire $\mathrm{O}$, Arch $\mathrm{E}$, et al. A loss-of-function mutation in the endothelin-converting enzyme 1 (ECE-1) associated with Hirschsprung disease, cardiac defects, and autonomic dysfunction. Am J Hum Genet. 1999:64:304-8

33. Bär KJ, Facer $P$, Williams NS, et al. Glial-derived neurotrophic factor in human adult and fetal intestine and in Hirschsprung's disease. Gastroenterology. 1997;112:1381-5.

34. Martucciello G, Thompson H, Mazzola C, et al. GDNF deficit in Hirschsprung's disease. J Pediatr Surg. 1998;33:99-102.

35. Moore SW, Zaahl MG. Association of endothelin-beta receptor (EDNRB) gene variants in anorectal malformations. J Pediatr Surg. 2007;42:1266-70.

36. Inoue K, Shimotake T, Iwai N. Mutational analysis of RET/GDNF/NTN genes in children with total colonic aganglionosis with small bowel involvement. Am J Med Genet. 2000;93:278-84.

37. Stanchina L, Baral V, Robert F, et al. Interactions between Sox10, Edn3 and Ednrb during enteric nervous system and melanocyte development. Dev Biol. 2006;295:232-49.

38. Tomiyama H, Shimotake $\mathrm{T}$, Ono $\mathrm{S}$, et al. Relationship between the type of RET/GDNF/NTN or SOX10 gene mutations and long-term results after surgery for total colonic aganglionosis with small bowel involvement. J Pediatr Surg. 2001;36:1685-8.

39. Roe KA, Syme HM, Brooks HW. Congenital large intestinal hypoganglionosis in a domestic shorthair kitten. J Feline Med Surg. 2010;12:418-20.

40. Stockhofe-Zurwieden N, Buijs RM, De Jong M. Megacolon in pigs due to segmental colon aganglionosis. Dtsch Tierarztl Wochenschr. 2001;108:267-9.

41. Brann L, Furtado D, Migliazzo CV, et al. Secondary effects of aganglionosis in the piebald-lethal mouse model of Hirschsprung's disease. Lab Anim Sci. 1977;27:946-54.

42. Hotta R, Cheng LS, Graham HK, et al. Isogenic enteric neural progenitor cells can replace missing neurons and glia in mice with Hirschsprung disease. Neurogastroenterol Motil. 2016;28:498-512.

43. Rosin E, Walshaw R, Mehlhaff $C$, et al. Subtotal colectomy for treatment of chronic constipation associated with idiopathic megacolon in cats: 38 cases (1979-1985). J Am Vet Med Assoc. 1988;193:850-3.

44. Goldstein AM, Hofstra RM, Burns AJ. Building a brain in the gut: development of the enteric nervous system. Clin Genet. 2013;83:307-16.

45. Lake Jl, Heuckeroth RO. Enteric nervous system development: migration, differentiation, and disease. Am J Physiol Gastrointest Liver Physiol. 2013; 305:G1-G24.
46. Hoehner JC, Wester T, Påhlman S, et al. Alterations in neurotrophin and neurotrophin-receptor localization in Hirschsprung's disease. J Pediatr Surg. 1996;31:1524-9.

47. Kuroda T, Ueda M, Nakano M, et al. Altered production of nerve growth factor in aganglionic intestines. J Pediatr Surg. 1994;29:288-93.

48. Chalazonitis A. Neurotrophin-3 in the development of the enteric nervous system. Prog Brain Res. 2004;146:243-63.

49. Louw JH, Barnard CN. Congenital intestinal atresia; observations on its origin. Lancet. 1955;269(6899):1065-7.

50. Louw JH. Congenital intestinal atresia and stenosis in the newborn. Observations on its pathogenesis and treatment. Ann R Coll Surg Engl. 1959;25:209-34.

51. van der Gaag I, Tibboel D. Intestinal atresia and stenosis in animals: a report of 34 cases. Vet Pathol. 1980;17:565-74.

52. Uzal FA, Plattner BL, Hostettter JM. Pathology of domestic animals. In Jubb, Kennedy \& Palmer's. ed. Elsevier. 6th ed. London: Saunders Ltd; 2016. p. 904-5.

53. Memarzadeh M, Talebi A, Edalaty M, et al. Hirschsprung's disease diagnosis: comparison of immunohistochemical, hematoxilin and eosin staining. J Indian Assoc Pediatr Surg. 2009;14:59-62.

54. Morales A, Morimoto S, Vilchis F, et al. Molecular expression of vascular endothelial growth factor, prokineticin receptor-1 and other biomarkers in infiltrating canalicular carcinoma of the breast. Oncol Lett. 2016;12:2720-7.

55. Ciaputa R, Nowak M, Madej JA, et al. Inhibin-a, E-cadherin, calretinin and Ki67 antigen in the immunohistochemical evaluation of canine and human testicular neoplasms. Folia Histochem Cytobiol. 2014;52:326-34.

56. Johnston HM, Thompson H, Pirie HM. p53 immunohistochemistry in domestic animal tumours. Eur J Vet Pathol. 1996;2:135-40.

57. Piñeyro P, Vieson MD, Ramos-Vara JA, et al. Histopathological and immunohistochemical findings of primary and metastatic medullary thyroid carcinoma in a young dog. J Vet Sci. 2014;15:449-53.

58. Akihisa S, Tetsuya S. Intestinal gastrointestinal stromal tumor in a cat. J Vet Med Sci. 2017;79:562-6.

59. Hugen S, Thomas RE, German AJ, et al. Gastric carcinoma in canines and humans, a review. Vet Comp Oncol. 2016;15:692-705.

60. Tam PK, Lister J. Development profile of neuron-specific enolase in human gut and its implications in Hirschsprung's disease. Gastroenterology. 1986; 90:1901-6.

61. Marangos PJ, Polak JM, Pearse AGE. Neuron-specific enolase: A probe for neurons and neuroendocrine cells. Trends Neurosci. 1982:5:193-6.

62. Metallinos DL, Bowling AT, Rine J. A missense mutation in the endothelin-B receptor gene is associated with lethal white foal syndrome: an equine version of Hirschsprung disease. Mamm Genome. 1998:9:426-31.

63. Washabau RJ, Holt D. Pathogenesis, diagnosis, and therapy of feline idiopathic megacolon. Vet Clin North Am Small Anim Pract. 1999:29:589-603.

64. Washabau R, Stalis I. Alterations in colonic smooth muscle function in cats with idiopathic megacolon. Am J Vet Res. 1996;57:580-6.

65. Le Douarin NM, Teillet MA. The migration of neural crest cells to the wall of the digestive tract in avian embryo. J Embryol Exp Morphol. 1973;30:31-48.

66. Le Douarin N, Teillet MA. Origin of intramural ganglionic system cells of the digestive tract of bird embryos. CR Acad Sci Hebd Seances Acad Sci D. 1971;273:1411-4.

67. Green SA, Uy BR, Bronner ME. Ancient evolutionary origin of vertebrate enteric neurons from trunk-derived neural crest. Nature. 2017:544(7648):88-91.

68. Forzán MJ, McClure JT. Congenital aganglionosis in a 3-day-old Holstein calf. Can Vet J. 2005:46:342-4

69. Lighbody T. Foal with overo lethal white syndrome born to a registered quarter horse mare. Can Vet J. 2002;43:715-7.

70. Swaminathan M, Kapur RP. Counting myenteric ganglion cells in histologic sections: an empirical approach. Hum Pathol. 2010;41:1097-108.

71. Anbardar MH, Geramizadeh B, Foroutan HR. Evaluation of Calretinin as a new marker in the diagnosis of Hirschsprung disease. Iran J Pediatr. 2015;25: e367

72. Jiang M, Li K, Li S, et al. Calretinin, S100 and protein gene product 9.5 immunostaining of rectal suction biopsies in the diagnosis of Hirschsprung' disease. Am J Transl Res. 2016;8:3159-68 eCollection 2016. 